\title{
Evaluation of knowledge, attitudes, and screening practices about cancer risk factors among health care professionals
}

\section{Zahra Sheikhalipour}

Hematology and Oncology Research Center. Tabriz University of Medical Sciences

Akram Ghahramanian

Hematology and Oncology Research Center. Tabriz University of Medical Sciences

Zohreh Sanaat

Hematology and Oncology Research Center. Tabriz University of Medical Sciences

Leila Vahedi ( $\square$ Vahedi.149@gmail.com )

Liver and Gastrointestinal Diseases Research Center. Tabriz University of Medical Sciences

Research article

Keywords: Cancer awareness, Knowledge, Attitudes, Screening, Practice

Posted Date: April 9th, 2020

DOI: https://doi.org/10.21203/rs.3.rs-21540/v1

License: (c) (i) This work is licensed under a Creative Commons Attribution 4.0 International License.

Read Full License 


\section{Abstract}

Background: Given the importance of health care personnel's awareness of cancer symptoms, this study aimed to investigate their knowledge regarding cancer warning symptoms, attitudes toward cancer risk factors, and performance on undertaking cancer screening tests.

Methods: This was a cross-sectional study which 145 health care staff working in the medical centers affiliated with Tabriz University of Medical Sciences prticipated in it. The study population included nurses, midwives, operating room technicians, laboratory staff, anesthesiologists and radiologists. Items assessing awareness of cancer warning signs, risk factors, incidence, screening programmes were extracted from the literature.

Results: The mean knowledge score of health care staffs was $7.97 \pm 2.01$. Regarding the staff's attitude toward the role of risk factors in increasing the likelihood of cancer, the results showed an average attitude score of $35.41 \pm 4.69$. Concerning the performance of the participants in cancer screening tests, the results showed that out of 125 women aged $25-57$ years, only $44 \%$ performed monthly selfexaminations, $22.1 \%$ referred to a specialist physician for breast cancer screening every three years and only $20.51 \%$ of the female participants aged over 40 years old performed mammography. In terms of cervical cancer screening in female participants, $27.2 \%$ had performed annual Pap smear tests, and $17.6 \%$ referred to a specialist for annual pelvic examinations. Regarding colorectal cancer screening in staff older than 45 years, our findings showed that from 24 participants ( $16.6 \%$ of the samples), only one had undertaken occult blood test and performed colonoscopy.

Conclusions: Because the public health depends on the wellness of health care professionals and their awareness of cancer warning signs, as well as their knowledge of cancer risk factors and adherence to cancer screening tests, they should be encouraged to perform these examinations.

\section{Background}

Cancer is one of the most important causes of death around the world. Currently, more than 10 million new cancer cases are diagnosed annually causing approximately 6 million deaths in the world [1]. It is estimated that by the year 2030, the world population will reach 7.5 billion, out of which 15 million will have cancer, and 12 million will die of the disease [2]. Reviewing the literature shows that there is a lack of awareness of cancer symptoms and signs and their importance. This is one of the main reasons for delay in referral to physician and consequently an increase in cancer-related mortality [3].

In Iran, cancer-related mortality is ranked third after cardiovascular diseases and accidents. Approximately 70,000 new cancer cases are diagnosed, and 35,000 related deaths are reporting in Iran annually. In general, the most common types of neoplasms in Iran (age-standardized) include skin, stomach, bladder, prostate and colorectal cancers in men, and breast, skin, colorectal, stomach and esophageal cancers in women. Overall, most frequent cancers in Iran are skin, stomach, breast, colorectal and bladder [4]. 
Today, unlike ancient times, cancer is no longer associated with inevitable death, and recent advances in technology have changed cancers from deadly and uncurable to chronic and treatable diseases. On the other hand, many cancers are preventable, so if proper action is already started to prevent them, it is expected that 2 million lives to be saved by 2020 [5]. Therefore, recognizing the warning signs of cancer and taking necessary measures such as performing diagnostic tests can be effective ways to prevent the incidence or progression of cancer [6].

According to these, the general population needs to be aware of the cancer warning signs and preventing actions. The warning symptoms can include changes in bowel/bladder habits, sore that does not heal, unexplained bleeding, lump or swelling, difficulty in swallowing, changes in the appearance of moles or warts, difficulty in digestion, persistent cough or hoarseness, and unexplained weight loss [1].

Few studies have been conducted on cancer awareness worldwide. The results of several studies have shown that people's awareness on warning signs of cancer is low in India, England and France [7-10]. Most similar studies in Iran have been related to women's cancers such as breast and cervix [11, 12]. There have been two studies regarding the public awareness of cancer warning symptoms In Iran. The first study was carried out by Zulfaqari et al. in Tehran which showed that most people's awareness and frequency of performing screening tests were at undesirable levels [1]. In the second study conducted by Jamali et al., most people's knowledge was reported at a moderate level $[8,9]$.

A review on the literature showed that there are few studies on the awareness of cancer symptoms and protective measures among health care personnel [1]. Since one of the tasks of health care staff is to educate patients and the general public about the signs and symptoms of cancer and respective diagnostic and preventive measures; therefore, awareness of the personnel about these issues can play an important role to prevent cancer in the community. Health care staff who have inadequate awareness of cancer warning symptoms may not be able to properly guide people in recognizing these symptoms and timely referring to a physician. This subsequently endangers the community's general health and fades the chance for exploiting appropriate preventive measures and a healthy lifestyle [13]. Given the importance of health care personnel's awareness of cancer symptoms, this study aimed to investigate their knowledge regarding cancer warning symptoms, attitudes toward cancer risk factors, and performance on undertaking cancer screening tests. We finally assessed the relationships between the knowledge, attitude and the performance on cancer screening tests.

\section{Methods}

\section{Study and population}

This was a cross-sectional study aiming to determine the awareness of health care staff working in the medical centers affiliated with Tabriz University of Medical Sciences regarding the warning signs of and protective measures against cancer. The study population included nurses, midwives, operating room technicians, laboratory staff, anesthesiologists and radiologists. 
Inclusion criteria were having either diploma, associate, bachelor's, master's and doctorate degrees in one of the above-mentioned fields, having no cancer according to self-reports, desire to participate in the study, and being over 30 years old.

Based on similar studies and considering $95 \%$ confidence interval, the mean of 4.25 , an acceptable error rate of 0.1 , and sample loss of $30 \%$, the sample size was estimated as 150 . These were selected amongst eligible individuals by simple random sampling. Finally, a total of 145 people participated in the study. Nurses comprised the largest group of the participants.

\section{Questionnaires}

The validity of the questionnaire was checked by face and content validities. The initial questionnaire was designed based on the literature and provided to 10 faculty members of Tabriz University of Medical Sciences, and necessary changes were made to the questionnaire based on their comments. The reliability of the questionnaire was determined by performing a guiding study on 30 personnel using the Kuder-Richardson 21 method.

The questionnaire consisted of four parts. The first part was related to the participants' demographic characteristics including age, sex, marital status, education, occupation, type of employment, place of work, and history of cancer in family members or friends.

The second part consisted of 9 closed-ended questions designed to determine the awareness of cancer warning signs including changes in bowel/ bladder habits, Sore that does not heal, unexplained bleeding, Lump or swelling, difficulty in swallowing, changes in the appearance of moles or warts, difficulty in digestion, persistent cough or hoarseness, and unexplained weight loss These symptoms were presented in 9 statements, and the participants were asked to select whether or not the statements were true. Each correct answer was scored 1 , and the wrong answer was scored 0 . The highest score was 9 , and the lowest was zero. A higher score indicated better awareness of the warning signs.

The third part of the questionnaire was designed to determine the staff's attitude toward the role of risk factors in the incidence of cancer. This part included 11 items in a four-point Likert scale ranging from strongly agree (score 4) to strongly disagree (score 1). The participants were asked to rate their agreement on each statement. The highest and lowest scores were 44 and 11, respectively, and a higher score indicated a better attitude toward the role of managing risk factors to prevent cancer. The assessed risk factors included smoking, being exposed to secondhand smoke, sunburn, overweight (BMI above 25), alcohol abuse (consuming more than one glass daily), low physical activity (exercising less than 30 minutes for 5 days a week), consuming fruit and vegetables poor diets, consuming red meat one or more occasions per day, age over 70 years old, and a family history of cancer.

The fourth section of the questionnaire was related to the extent of performing cancer screening tests and was developed according to the American Cancer Society's Guidelines. This part was designed to measure the tendency of health care staff for undertaking cancer screening tests including annual 
periodic examinations, regular oral examinations, endoscopy, periodic blood tests, urine and fecal tests, rectal examination, hepatitis $B$ vaccination, prostate and testicular examinations, and mammography in those over 45 years old.

\section{Statistical analysis}

Descriptive statistics including frequency, percentage, mean and standard deviation were used to present the demographic data. Also, the frequency of performing screening tests was described in age groups recommended by the American Cancer Society for breast, cervical and colorectal cancers. Analytical statistics including independent Sample t-test and analysis of variance were used to assess the relationship between knowledge, attitude and performance on cancer screening tests. The abovementioned statistical tests along with Pearson's correlation were used to determine the relationship between demographic and occupational variables with the participants' knowledge and attitude.

\section{Results}

\section{Demographic characteristics}

The most of the participants were female (82.6\%), married (85.5\%), nurse (71\%) and had a bachelor's degree (83.4\%). The mean age of the participants was $37.42 \pm 5.73$ years. Our results indicated that there was no significant relationship between demographic and occupational variables with the knowledge of cancer symptoms and attitude toward cancer risk factors among the nurses (Table 1).

The mean knowledge score of health care staff was $7.97 \pm 2.01$. The symptom of "stiffness or presence of masses in the breast or other organs" was designated by the majority of the participants as a warning sign. Difficulty in digestion and dyspepsia were most common wrong-answered symptoms by the participants (94.5\%). (Table 2)

Regarding the staff's attitude toward the role of risk factors in increasing the likelihood of cancer, the results showed an average attitude score of $35.41 \pm 4.69$. Overall, $78.6 \%$ and $64.1 \%$ of the participants strongly agreed with the role of smoking and being exposed to smoking. Furthermore, alcohol abuse and having a family history of cancer attained subsequent ranks with full agreement rates of $60.7 \%$ and $52.4 \%$, respectively. (Table 3 )

Concerning the performance of the participants in cancer screening tests, the results showed that out of 125 women aged $25-57$ years, only $44 \%$ performed monthly self-examinations, and although their knowledge and attitude about cancer warning symptoms were better than those who do not self-tested, but the difference was not statistically significant ( $P$-value $>0.3)$. Also, of females aged between 20 and 39 years old (who consisted $68.8 \%$ of participating women), $22.1 \%$ referred to a specialist physician for

breast cancer screening every three years. Although these women's knowledge and attitude about cancer warning signs were better than those who performed no clinical examinations, the difference was not 
statistically significant ( $P$-value $>0.2)$. Of women aged 40 years and older (who consisted $31.2 \%$ of female participants), $28.2 \%$ referred to a specialist annually.

In terms of screening for breast cancer, only $20.51 \%$ of the female participants aged over 40 years old performed mammography. Although the knowledge and attitude of these women were higher than those without screening, the difference between the two groups was not statistically significant $(P$-value $>0.3)$.

In terms of cervical cancer screening in female participants, $27.2 \%$ had performed annual Pap smear tests, and $17.6 \%$ referred to a specialist for annual pelvic examinations (Table 4). There was no significant difference in the mean score of knowledge of cancer warning symptoms between women with and without cervical cancer screening $(P$-value $>0.1)$; however, those who performed Pap smear and pelvic examination had better attitudes toward the role of cancer risk factors $(P$-value $>0.5)$.

Regarding colorectal cancer screening in staff older than 45 years, our findings showed that from 24 participants ( $16.6 \%$ of the samples), only one had undertaken occult blood test and performed colonoscopy (Table 4). Due to the low number of men in this study, and the fact that they were younger than 50 years and did not meet the criteria for prostate cancer screening, no analysis was performed on this issue.

\section{Discussion}

According to our results, most of the participants in this study were female, nurse, and had a bachelor's degree, which was in line with the study of Cook et al. (2011) in which the majority of subjects were female, had a bachelor's degree, and aged 25-64 years old. In the present study, most participants acquired their information about cancer warning signs through college courses. However, in the study of Cook et al., most of the participants had acquired their knowledge about cancer symptoms through their self-studies while pamphlets and posters had the least roles in augmenting their information [13]. The results of the Mahajan SM et al. (2017) also showed that most nurses obtained their information about cervical cancer warning signs through various ways at hospital environment [14].

Most of our participants answered "yes" when they were asked whether a specific symptom was a cancer warning sign or not. In this regard, most of them answered "yes" to the question regarding the "stiffness or presence of masses in the breast or other organs". On the other hand, questioning about digestion or dyspepsia, the least of participants were aware of this symptom. In the study of Zulfaqari et al. who evaluated the awareness of cancer warning symptoms in Tehran, the results showed that the majority of participants acknowledged the "stiffness or the presence of masses" and the "sudden weight loss" as the main warning signs of cancer. In other studies, difficult to heal ulcers, persistent cough, violent voice, and unexplained pain were among other most recognized cancer warning signs [1].

Assessing cancer risk factors, most of the participants designated the smoking and daily alcohol abuse as cancer risk factors. Also, most participants strongly agreed with the family history of cancer as a risk factor. In line, other studies have also recognized smoking and alcohol abuse as cancer risk factors. In a 
study by Shivakumar et al., (2017) participants acknowledged smoking and alcohol abuse as risk factors of oral cancer [15].

Regarding performance in cancer screening tests and preventive measures, although our staff were aware of the cancer warning signs, their adherence to screening tests was at a very low level. Accordingly, only few female participants, mostly nurses, either performed breast cancer self-examinations or referred to specialist physicians for periodic examinations and mammograms. The same was true for cervical cancer screening and Pap smear testing. This is while nurses have important roles in educating the public about screening tests, preventive measures, and symptoms of cancer. Actually, performing these roles is not possible until they truly believe in these actions; otherwise, they cannot educate the public regarding cancer screening tests. Jain et al. (2016) also described that nurses had low knowledge about the symptoms of cervical cancer and the necessity of performing the Pap smear test. Therefore, these nurses had little enthusiasm to encourage others to do such examinations [16].

Our findings also indicated that male participants had not tendency to perform prostate examinations. This is while these personnel had the opportunity to undertake these procedures in their workplace. The Tasian et al.'s study (2012) on the knowledge and awareness of medical staff reported their low knowledge about screening tests and risk factors of prostate cancer [17]. In another study by Firzara et al. (2016) on health care staff, in addition to have a good knowledge on prostate cancer and its screening tests, $89 \%$ of the participants had performed these tests [18].

Considering colon cancer, most of our participants did not perform screening tests. The results also showed that the most of the participants did not perform general checkups for thyroid, testicular, ovarian, lymph node, oral and skin cancers which should be done every three years. This is while in recent years, we have seen mortalities in health care personnel including physicians, nurses, and midwives because of various cancers including colon, breast, and stomach.

\section{Conclusions}

Most of our participants were aware of cancer warning signs; nevertheless, they did not perform preventive screening measures on a regular basis. Regarding that health care personnel have a responsibility for educating and encouraging general public to have periodic examinations for cancer, it is recommended to ascertain the reasons of their reluctance to perform periodic examinations. As well, because the public health depends on the wellness of health care professionals and their awareness of cancer warning signs, as well as their knowledge of cancer risk factors and adherence to cancer screening tests, they should be encouraged to perform these examinations.

\section{Limitation:}

The present study has several limitations. 1) The current study has only been studied among staffs over 30 years of age and in the government hospitals. 2) This study has not surveyed the views of physicians. 


\section{Declarations}

\section{Ethics approval and consent to participate}

The study was approved by the Ethics Committee in Research of Tabriz University of Medical Sciences. Data was gathered after approval by the deputy of research of Tabriz University of Medical Sciences. The researchers then identified and randomly selected eligible subjects and collected their information after obtaining informed consent (IR.Tbzmed.rec.5/4/6559).

\section{Consent for publication}

We used from questionnaire.The names of staffs have not been taken and the code has been used for them. Availability of data and material the datasets used and analyzed during this study are accessible from the corresponding author and first author and are not available through Hematology and Oncology Research Center of Tabriz University of Medical Sciences.

\section{Competing interests}

The authors declare that they have no competing interests.

\section{Funding}

The authors wish to disclose receipt of the following financial support for the research, authorship and/or publication of this article. This work was supported by the Deputy for Research and Technology, Tabriz University of Medical Sciences.

\section{Authors' contributions}

ShZ and SZ: Selection of title. ShZ and SZ: Designing of the study. ShZ, GA and SZ: Setting up the Questionnaire. ShZ, GA and VL: data collection, GA and VL: Performing the statistical analysis. ShZ, GA, SZ and VL: Interpreting the data. ShZ and SZ: Taking ethical code. ShZ , GA, SZ and VL: Editing the study. All authors read and approved the final manuscript.

\section{Acknowledgments}

We would like to sincerely thank the participants for taking part in the research process. Moreever, we would like to thank staffs of, Hematology and Oncology Research Center of Medical Sciences in Tabriz/Iran because of their collaboration in the advancing this study.

\section{References}

1. Zolfaghari M, Parsayekta Z, Bahramnejad F, Kazemnejad A, Monjamed Z. Tehran's people awareness of the seven signs of cancer and application of protective actions against cancer. Payesh Journal. 2010;9(3):317-24.

2. Jemal A, Siegel R, Xu J, Ward E. Cancer statistics, 2010. CA Cancer J Clin. 2010;60(5):277-300.

3. Robb K, Stubbings S, Ramirez A, Macleod U, Austoker J, Waller J, et al. Public awareness of cancer in Britain: a population-based survey of adults. Br J Cancer. 2009;101:18-23. 
4. Sadjadi A, Nouraie M, Mohagheghi M, Mousavi-Jarrahi A, Malekezadeh R, Parkin D. Cancer occurrence in Iran in 2002, an international perspective. Asian Pac J Cancer Prev. 2005;6(3):359-63.

5. Sedighi Z, Vahdaninia M, Khodabandeh A, Jarvandi F. Women knowledge about servix cancer and the effect of educational booklet on their knowledge. Payesh Journal. 2004;4(1):29-38.

6. Jemal A, Siegel R, Ward E, Murray T, Xu J, Thun MJ. Cancer statistics, 2007. CA Cancer J Clin. 2007;57(1):43-66.

7. McMenamin $M$, Barry $H$, Lennon A-M, Purcell $H$, Baum $M$, Keegan $D$, et al. A survey of breast cancer awareness and knowledge in a Western population: lots of light but little illumination. Eur $\mathrm{J}$ Cancer. 2005;41(3):393-7.

8. Miles A, Waller J, Hiom S, Swanston D. SunSmart? Skin cancer knowledge and preventive behaviour in a British population representative sample. Health Educ Res. 2005;20(5):579-85.

9. Janda M, Youl P, Lowe J, Elwood M, Ring I, Aitken J. Attitudes and intentions in relation to skin checks for early signs of skin cancer. Prev Med. 2004;39(1):11-8.

10. Pullyblank A, Cawthorn S, Dixon A. Knowledge of cancer symptoms among patients attending onestop breast and rectal bleeding clinics. EJSO. 2002;28(5):511-5.

11. Yavari P, Mehrabi Y, Porhoseingholi M. Knowledge and practice of breast self-examination among women: a case-control study. J Ardabil Univ Med Sci. 2005;5(4):371-4.

12. Azizi mohammadi S, Vakili M, Mosavinasab N, Kiani K, Vaziri K. Student knowledge, attitudes and skills about breast cancer. Journal of Zanjan University of Medical Sciences \& Health Servicees. 2001;9(34).

13. Cook N, Hart A, Nuttall K, Simpson K, Turnill N, Grant-Pearce C, et al. A telephone survey of cancer awareness among frontline staff: informing training needs. Br J Cancer. 2011;105(3):340-5.

14. Swati M, Mahajan VS, Jadhav AR, Magare SA, Adchitre, Salve SB. Awareness and screening practices of cervical cancer among nursing staff working in tertiary care hospital. Int $\mathrm{J}$ Community Med Public Health. 2017;4(10):3590-5.

15. Shivakumar KM. Prevalence of Oral Cancer Screening Practices and Awareness among the Nursing Staff of Karad City, India. Critical care. 2017;50:12.5.

16. Jain S, Bagde M, Bagde N. Awareness of cervical cancer and Pap smear among nursing staff at a rural tertiary care hospital in Central India. Indian J cancer. 2016;53(1):63.

17. Tasian GE, Cooperberg MR, Cowan JE, Keyashian K, Greene KL, Daniels NA et al, editors. Prostate specific antigen screening for prostate cancer: knowledge of, attitudes towards, and utilization among primary care physicians. UROL ONCOL-SEMIN ORI; 2012: Elsevier.

18. Firzara AMT, $\mathrm{Ng}$ CJ. Knowledge and practice of prostate cancer screening among general practitioners in Malaysia: a cross-sectional study. BMJ open. 2016;6(9).

\section{Tables}

Table 1: Characteristics and relationship them to knowledge and attitude of participants $(n=145)$ 


\begin{tabular}{|c|c|c|c|c|c|c|}
\hline Variables & Characteristics & $\mathrm{F}(\%)$ & Knowledge & $P$-value & Attitude & $P$-value \\
\hline \multirow[t]{4}{*}{ Gender } & Male & $20(13.8)$ & $7.95(1.82)$ & 0.9 & 33.95 & 0.1 \\
\hline & & & & & $(5.06)$ & \\
\hline & Female & $125(86.2)$ & $7.98(2.04)$ & & 35.64 & \\
\hline & & & & & $(4.60)$ & \\
\hline \multirow[t]{4}{*}{ Marital status } & Unmarried & $21(14.48)$ & $7.68(2.56)$ & 0.8 & 33.89 & 0.5 \\
\hline & & & & & $(5.76)$ & \\
\hline & Married & $124(85.52)$ & $8.01(1.93)$ & & 35.66 & \\
\hline & & & & & $(4.51)$ & \\
\hline \multirow{2}{*}{$\begin{array}{l}\text { History of cancerin the family/ } \\
\text { relatives }\end{array}$} & Yes & $44(30.3)$ & $7.60(2.39)$ & 0.1 & $35.23(4.92)$ & 0.6 \\
\hline & No & 101 (69.7) & $8.14(1.79)$ & & $35.57(4.55)$ & \\
\hline \multirow[t]{4}{*}{ Relation of person with cancer } & Parents & $25(56.8)$ & $7.84(2.37)$ & 0.7 & 34.04 & 0.1 \\
\hline & & & & & $(4.94)$ & \\
\hline & Relatives & $19(43.1)$ & $7.63(1.86)$ & & 36.42 & \\
\hline & & & & & $(4.50)$ & \\
\hline \multirow[t]{10}{*}{ Position } & Nursing & $103(71)$ & $8.04(2.05)$ & 0.9 & $35(4.92)$ & 0.4 \\
\hline & laboratory sciences & $9(6.2)$ & $7.55(2.45)$ & & $35(3.96)$ & \\
\hline & Radiology & $9(6.2)$ & $8.11(.92)$ & & 36.44 & \\
\hline & & & & & (3.35) & \\
\hline & Anesthesiology & $8(5.5)$ & $7.62(1.30)$ & & 35.75 & \\
\hline & & & & & $(4.23)$ & \\
\hline & Midwifery & $7(4.8)$ & $7.42(3.30)$ & & 38.42 & \\
\hline & & & & & $(3.86)$ & \\
\hline & Operating & $9(6.2)$ & $8.22(1.30)$ & & 36.77 & \\
\hline & roomtechnician & & & & $(4.32)$ & \\
\hline \multirow[t]{5}{*}{ Education level } & Under bachelor & $12(8.3)$ & $7.25(3.44)$ & 0.3 & 34.66 & 0.4 \\
\hline & & & & & $(4.67)$ & \\
\hline & Bachelor & $121(83.4)$ & $8.06(1.81)$ & & 35.61 & \\
\hline & & & & & $(4.68)$ & \\
\hline & Master & $11(7.6)$ & $7.81(2.18)$ & & $34(4.83)$ & \\
\hline \multirow[t]{2}{*}{ Age (year) (Mean \pm SD) } & & $37.42 \pm$ & $7.97 \pm 2.01$ & $0.03 \pm 0.6$ & $35.41 \pm$ & $-0.002 \pm$ \\
\hline & & 5.72 & & & 4.68 & 0.9 \\
\hline Work Experience (year) & & $12.93 \pm$ & $7.97 \pm 2.01$ & $0.02 \pm 0.8$ & $35.41 \pm$ & $-0.02 \pm 0.8$ \\
\hline$(\mathrm{Mean} \pm \mathrm{SD})$ & & 5.24 & & & 4.68 & \\
\hline
\end{tabular}

Table 2: Knowledge of participants toward the warning signs \& symptoms of cancer 


\begin{tabular}{lcc}
\hline Questions & False & True \\
N (\%) & N (\%) \\
\hline Changes in bowel/ bladder habits & $22(15.2)$ & $123(84.8)$ \\
\hline Sore that does not heal & $24(16.6)$ & $121(83.4)$ \\
\hline Unexplained bleeding & $11(7.6)$ & $134(92.4)$ \\
\hline Lump or swelling & $8(5.5)$ & $137(94.5)$ \\
\hline Difficulty in swallowing & $16(11)$ & $129(89)$ \\
\hline Change in appearance of mole or wart & $12(8.3)$ & $133(91.7)$ \\
\hline Difficulty in digestion & $25(17.2)$ & $120(82.8)$ \\
\hline Persistent cough or hoarseness & $20(13.8)$ & $125(86.2)$ \\
\hline Unexplained weight loss & $10(6.9)$ & $135(93.1)$ \\
\hline & Range & Mean (SD) \\
\hline Total score & $1-9$ & $7.97(2.01)$ \\
\hline
\end{tabular}

Table 3: Attitudes about the role of risk factors in increasing the chances of cancers.

\begin{tabular}{lcccc}
\hline Attitude items & Completely disagree & Disagree & Agree & Completely agree \\
\hline Smoking & - & $4(2.8)$ & $27(18.6)$ & $114(78.6)$ \\
\hline Passive smoking & $1(0.7)$ & $7(4.8)$ & $44(30.3)$ & $93(64.1)$ \\
\hline Sun burn & $1(0.7)$ & $13(9)$ & $71(49)$ & $60(41.4)$ \\
\hline Overweight & $5(3.4)$ & $31(21.4)$ & $73(50.3)$ & $36(24.8)$ \\
\hline Alcohol Drinking & $1(0.7)$ & $11(7.6)$ & $45(31)$ & $88(60.7)$ \\
\hline Low exercise and physical activity & $9(6.2)$ & $49(33.8)$ & $58(40)$ & $29(20)$ \\
\hline Low consumption of fruits and vegetables & $2(1.4)$ & $19(13.1)$ & $63(43.4)$ & $61(42.1)$ \\
\hline High intake of high cholesterol meats & $1(0.7)$ & $45(31)$ & $69(47.6)$ & $30(20.7)$ \\
\hline Age & $4(2.8)$ & $51(35.2)$ & $59(40.7)$ & $31(21.4)$ \\
\hline Family history of cancer & $1(0.7)$ & $9(6.2)$ & $59(40.7)$ & $76(52.4)$ \\
\hline Hepatitis B virus infection & - & $21(14.5)$ & $82(56.6)$ & $42(29)$ \\
\hline Total score (Mean \pm SD) & $35.41 \pm 4.68$ & & & \\
\hline
\end{tabular}

Table 4: Screening performance of participants about cancers. 


\begin{tabular}{|c|c|c|c|c|c|c|c|c|}
\hline & Questions & $\begin{array}{c}\text { Sample size } \\
\text { N (\%) }\end{array}$ & & $\begin{array}{c}\text { I do } \\
\text { N (\%) } \\
\end{array}$ & $\begin{array}{l}\text { Knowledge } \\
\text { Mean (SD) }\end{array}$ & $P$-value & $\begin{array}{c}\text { Attitude } \\
\text { Mean (SD) }\end{array}$ & $P$-value \\
\hline \multirow[t]{18}{*}{ Women's cancers $(n=125)$} & $\mathrm{BC} 1$ & $125(100)$ & Do & $55(44)$ & 8.17 (1.58) & 0.3 & $36(4.56)$ & 0.4 \\
\hline & & & Do not & $69(55.2)$ & $7.81(2.35)$ & & $35.40(4.67)$ & \\
\hline & & & Missed & $1(0.8)$ & - & & - & \\
\hline & BC2 & 20-39 Year & Do & $19(22.1)$ & $8.42(1.07)$ & 0.2 & $36.84(4.36)$ & 0.1 \\
\hline & & $86(68.8)$ & Do not & $64(74.7)$ & $7.78(2.22)$ & & $34.95(4.53)$ & \\
\hline & & & Missed & $3(3.5)$ & - & & - & \\
\hline & BC3 & $>40 y e a r$ & Do & $11(28.20)$ & $8.54(.82)$ & 0.3 & $38.90(2.65)$ & 0.06 \\
\hline & & $39(31.2)$ & Do not & $23(58.87)$ & $7.82(2.65)$ & & $35.47(5.25)$ & \\
\hline & & & Missed & $5(12.83)$ & - & & - & \\
\hline & BC4 & $>40 y e a r$ & Do & $8(20.51)$ & $8.50(0.92)$ & 0.5 & $38.75(4.23)$ & 0.1 \\
\hline & & $39(31.2)$ & Do not & $26(66.66)$ & $7.92(2.51)$ & & $35.80(5.20)$ & \\
\hline & & & Missed & $5(12.83)$ & - & & - & \\
\hline & Cervix Cancer 1 & $125(100)$ & Do & $34(27.2)$ & 8.38 (1.68) & 0.1 & $37.20(4.17)$ & 0.02 \\
\hline & & & Do not & $85(68)$ & $7.76(2.21)$ & & $35.08(4.72)$ & \\
\hline & & & Missed & $6(4.8)$ & - & & - & \\
\hline & Cervix Cancer 2 & $125(100)$ & Do & $22(17.6)$ & 8.22 (1.97) & 0.5 & $37.63(3.74)$ & 0.02 \\
\hline & & & Do not & $101(80.8)$ & $7.92(2.08)$ & & $35.27(4.70)$ & \\
\hline & & & Missed & $2(1.6)$ & - & & - & \\
\hline \multirow[t]{9}{*}{ Participants $(n=24)$} & Colorectal1 & $125(100)$ & Do & $1(4.16)$ & $9(00)$ & & $44(00)$ & \\
\hline & & & Do not & 9 (37.5) & $7.44(3)$ & & $34.33(7.58)$ & \\
\hline & & & Missed & $14(58.33)$ & - & & - & \\
\hline & Colorectal2 & $125(100)$ & Do & $1(4.16)$ & $9(00)$ & & $44(00)$ & \\
\hline & & & Do not & $8(33.34)$ & 7.25 (3.15) & & $34.25(8.10)$ & \\
\hline & & & Missed & $15(62.5)$ & & & & \\
\hline & Colorectal3 & $125(100)$ & Do & - & - & & - & \\
\hline & & & Do not & $8(33.34)$ & 7.25 (3.15) & & $34.75(8.61)$ & \\
\hline & & & Missed & $16(66.66)$ & - & & - & \\
\hline
\end{tabular}

